\title{
STUDIES ON EFFECT OF FORMULATION AND PROCESSING PARAMETERS ON STABILITY OF KETOROLAC TROMETHAMINE ORALLY DISSOLVING FILMS
}

\author{
NIDHI P. SAPKAL ${ }^{1 *}$, MINAL N. BONDE², MANGESH GAWANDE², ANWAR S. DAUD ${ }^{2}$
}

${ }^{1}$ Gurunanak College of Pharmacy, Kamgar Nagar, Nari, Nagpur, India, ${ }^{2 Z i m}$ Laboratories Limites, Kalmeshwar, Nagpur, India

Email: nidhi_sapkal@yahoo.co.in

Received: 13 Jan 2019, Revised and Accepted: 10 May 2019

\section{ABSTRACT}

Objective: The objective of the proposed work was to study the effect of various formulation and process parameters of solvent casting method on the physical and chemical stability of Ketorolac Tromethamine (KT) in the orally dissolving film dosage form.

Methods: KT-excipient interaction study was carried out both in solid state and by processing samples through the solvent casting technique. The samples were evaluated using IR spectroscopy (IR) and X-ray diffractometry (XRD). Solvent casting method was used to prepare KT films using different film-forming polymers, and solvents. The drying temperature and $\mathrm{pH}$ of the dispersion were also varied to study the effect of these parameters on the stability of KT. All the formulations were analysed chemically initially and after one month of storage at $40{ }^{\circ} \mathrm{C} / 75 \% \mathrm{RH}$.

Results: During KT-excipient interaction study in solid state KT was found to be stable. No significant changes were observed in its impurity profile. Interaction between different polymers and KT was observed after the solvent casting process as revealed by IR and XRD analysis. The interaction was further confirmed in the film formulations upon chemical analysis. The polymers showing interaction with KT in XRD and IR were making it unstable chemically and were responsible for its chemical degradation as revealed by chemical analysis. It was also revealed that KT is most stable when processed using water as the solvent. KT was found to be stable when processed at a higher temperature and at acidic pH during film formation. It was found that chemical stability is more when Polyethylene oxide (PEO) and water under acidic pH are used and films are dried at a higher temperature.

Conclusion: Both formulation parameters and processing conditions of the solvent casting technique affects the stability of drugs and hence should be studied as part of pre-formulation studies while developing orally dissolving films of drugs.

Keywords: Ketorolac, Tromethamine, Orally dissolving films

(C) 2019 The Authors. Published by Innovare Academic Sciences Pvt Ltd. This is an open access article under the CC BY license (http://creativecommons.org/licenses/by/4.0/) DOI: http://dx.doi.org/10.22159/ijap.2019v11i4.32026

\section{INTRODUCTION}

Orally disintegrating strips are relatively a new dosage form. These are very thin, rectangular, paper-like films that disintegrate quickly when kept on the tongue. These are becoming a very popular dosage form for special need patient population like pediatric, geriatric, dysphagic, mentally challenged and bedridden. Few products are already available in the market and many are under development.

These thin films are prepared using the solvent casting method. This method is distinctly different from manufacturing methods of other oral solid dosage forms. In the solvent casting method, all the ingredients are mixed uniformly in aqueous or hydro-alcoholic solvents to form a uniform dispersion of desired consistency. This dispersion is then spread in the form of a thin film of uniform thickness and dried in the drying chamber. The quantity of moisture and exposure to high temperature is significantly more in this process as compared to any other manufacturing process, like, granulation, tableting, pelletization, coating etc. Due to this, physicochemical interactions may take place that may affect the stability of the product. This might be the reason that despite being very useful dosage form, not many products are being launched in the market.

Ketorolac tromethamine (KT) is a salt of (RS)-5-benzoyl-2,3dihydro-1H-pyrrolizine-1-carboxylate with 2-amino-2(hydroxymethyl) propane-1,3-diol [1]. It has both anti-inflammatory and analgesic activity with the analgesic activity being 800 times more potent than aspirin [2]. Degradation behavior of KT has been studied by several researchers in the presence of different factors like $\mathrm{pH}$, temperature, oxidant, and light. The acidic, basic and neutral solution of the drug was found to degrade in hydrolytic, photolytic and thermal conditions but the solid form of the drug was found to be stable under photolytic condition [2-6]. Study of the literature suggests that KT being sensitive molecules may not yield stable film formulation when formulated into orally dissolving films using the solvent casting technique.
KT is already available commercially in the form of oral tablets [7], solution for injection [8], nasal sprays [9] and ophthalmic solutions [10]. Strategies for stabilizing KT in these formulations are already established and known. Some film based dosage forms of KT like, transdermal patches [11], nanocomposite ophthalmic films [12], sublingual films [13], orobuccal films [14] are reported in the literature, but none of them reports the effect of formulation and process parameters on the stability of KT.

The proposed work aims to study the effect of various film-forming polymers and process parameters of solvent casting method on the physical and chemical stability of KT in the orally dispersible film dosage form.

\section{MATERIALS AND METHODS}

\section{Materials}

KT was procured from Symed Labs. Commercial grade excipients Hypromellose (HPMC) and Polyethylene oxide (PEO) were purchased from Dow Chemicals, Hydroxypropyl cellulose (HPC) was from Ruitai and Kollicoat IR from BASF. The plasticizer Propylene glycol and antioxidant Butylated hydroxyanisole (BHA) were purchased from Finar Limited. All the excipients were stored as received under optimum storage conditions until use.

\section{Methods}

\section{Analytical method}

A complete analysis of impurities was determined using a Shimadzu HPLC system and C18 column (250 mm X $4.6 \mathrm{~m}, 5 \mu \mathrm{m}$ ) (Suprisorb ODS-100). The mobile phase was Methanol: Water: Glacial Acetic acid (550:440:10) with a flow rate of $1.2 \mathrm{ml} / \mathrm{min}$. The UV detector was used at $254 \mathrm{~nm}$. The column temperature was $30^{\circ} \mathrm{C}$.

Drug-excipient interaction study in the solid state

In a detailed KT-excipient interaction study, KT was intimately mixed with each excipient as per the ratio mentioned in table 1 
using clean glass mortar and pestle. Each mixture was then divided into two portions and placed in glass vials capped with perforated aluminum foil and was stored at $40{ }^{\circ} \mathrm{C} / 75 \% \mathrm{RH}$ for $30 \mathrm{~d}$. The mixtures were analyzed for chemical degradation using the HPLC method on Day 1 and after completion of studies. The results were compared with pure KT stored under similar conditions. Placebos for all the samples were also prepared and stored under similar conditions [15].

Table 1: Selected excipients and their ratio

\begin{tabular}{lll}
\hline S. No. & Excipient & Ratio with KT \\
\hline 1 & HPMC & $1: 1$ \\
2 & HPC & $1: 1$ \\
3 & Kollicoat IR & $1: 1$ \\
4 & PEO & $1: 1$ \\
5 & Propylene glycol & $1: 0.1$ \\
6 & BHA & $1: 0.1$ \\
\hline
\end{tabular}

\section{Drug-polymer interaction study under processing conditions}

To understand the behavior of KT in the presence of various filmforming polymers during the film forming process, KT was processed in the presence of selected film-forming polymers. For this, a solution of film-forming polymer/s (table 2) was prepared by dissolving about $50 \mathrm{~g}$ of polymer/s in about $100 \mathrm{ml}$ of water and kept overnight. About $10 \mathrm{~g}$ of KT was dissolved in this solution and stirred for $15 \mathrm{~min}$. The solution was then dried at $70{ }^{\circ} \mathrm{C}$. The dried powders were then pulverized and analyzed using IR spectroscopy (Shimadzu FTIR 8101) and X-ray diffractometry (Philips AnalyticalX'Pert PRO). The physical mixtures in a similar ratio were also prepared and analyzed for comparing the effect of processing conditions on the KT.

Table 2: Compositions of drug and polymer for studying the effect of processing conditions

\begin{tabular}{llll}
\hline S. No. & Mixture composition & Formulation code & Processed mixture \\
\cline { 3 - 4 } & & Physical mixture & KT1B \\
\hline 1 & KT+HPMC $(1: 1)$ & KT1A & KT2B \\
2 & KT+HPMC+HPC $(1: 0.5: 0.5)$ & KT2A & KT3B \\
3 & KT+Kollicoat $(1: 1)$ & KT3A & KT4B \\
4 & KT+PEO $(1: 1)$ & KT4A & KT5B \\
5 & KT+HPMC+Kollicoat $(1: 0.5: 0.5)$ & KT5A & KT6B \\
6 & KT+HPMC+PEO (1:0.5:0.5) & KT6A & \\
\hline
\end{tabular}

\section{Preparation of KT films using different polymers}

In this study, KT films were prepared using selected filmforming polymers and their mixtures. Solvent casting method was used for preparing these films [16, 17]. Literature revealed that KT undergoes degradation under acidic, basic, thermal and photolytic conditions. In most cases, the impurity produced is because of the oxidation of KT. So, care was taken to prepare a neutral solution in the presence of a suitable antioxidant and the whole process was carried out in diffused light. In a separate study, BHA was found to be a good antioxidant to prevent the generation of oxidation induced impurities. Therefore, BHA was added to all the formulations.
Table 3 gives the composition of each formulation. The film-forming polymer was dissolved in water and left overnight to obtain a homogenous mixture. Propylene glycol, KT and BHA were added into this mixture and stirred with the help of mechanical stirrer at a speed of $3000 \mathrm{rpm}$ for $15 \mathrm{~min}$. The solution was then degassed with the help of the vacuum. The casting dispersion so obtained was then uniformly cast on a polyester sheet with the help of a doctor's blade to a uniform thickness. The films were then dried in the drying chamber at $70{ }^{\circ} \mathrm{C}$ for 15 to $20 \mathrm{~min}$. All the operations were carried out under diffused light. The films so obtained were cut into suitable sizes and packed in triple layer aluminum pouches, sealed and stored at $40{ }^{\circ} \mathrm{C} / 75 \%$ RH for $30 \mathrm{~d}$. The films were evaluated initially and after a period of $30 \mathrm{~d}$ for the quantitative estimation of impurities.

Table 3: Film formulations of KT with the selected film-forming polymer/s

\begin{tabular}{|c|c|c|c|c|c|c|c|}
\hline \multirow[t]{2}{*}{ S. No. } & \multirow[t]{2}{*}{ Ingredients } & \multicolumn{6}{|c|}{ Composition in percent } \\
\hline & & F1 & F2 & F3 & F4 & F5 & F6 \\
\hline 1 & Ketorolac Tromethamine & 20 & 20 & 20 & 20 & 20 & - \\
\hline 2 & HPMC & 56 & - & - & - & - & - \\
\hline 3 & HPMC+HPC (1:1) & - & 56 & - & - & - & - \\
\hline 4 & Kollicoat IR & - & - & 56 & & - & - \\
\hline 5 & PEO & - & - & - & 56 & - & - \\
\hline 6 & HPMC+Kollicoat IR (1:1) & - & - & - & - & 56 & - \\
\hline 7 & HPMC+PEO (1:1) & - & - & - & - & - & 56 \\
\hline 8 & Propylene Glycol & 20 & 20 & 20 & 20 & 20 & - \\
\hline 9 & BHA & 4 & 4 & 4 & 4 & 4 & - \\
\hline 10 & Water & qs & qs & qs & qs & qs & qs \\
\hline
\end{tabular}

\section{Preparations of KT films using different solvents}

To investigate the role of solvents in the stability of KT, Formulation F6 was prepared using different casting solvents as given in table 4 . Method of preparation was the same as given in section 2.4, only water was replaced. If the quantity of IPA is increased beyond $40 \%$ in the solvent, good quality films were not obtained. This finding was in accordance with our earlier findings [18]. The films so obtained were cut, packed, sealed and stored at $40^{\circ} \mathrm{C} / 75 \% \mathrm{RH}$ for $30 \mathrm{~d}$.

The films were evaluated initially and after a period of $30 \mathrm{~d}$ for the determination of impurities. 
Table 4: Film formulations of KT prepared using different solvent systems

\begin{tabular}{lll}
\hline S. No. & Casting solvent & Formulation code \\
\hline 1 & Water & F6 \\
2 & Water: IPA $(80: 20)$ & F6A \\
3 & Water: IPA (70:30) & F6B \\
4 & Water: IPA $(60: 40)$ & F6C \\
\hline
\end{tabular}

\section{Preparation of KT films using different drying temperatures}

To evaluate the role of drying temperature on the stability, formulation F6 was formulated using the method described in section 2.4 and was dried at $70^{\circ} \mathrm{C}(\mathrm{F} 6), 50^{\circ} \mathrm{C}(\mathrm{F} 6 \mathrm{D})$ and $40{ }^{\circ} \mathrm{C}(\mathrm{F} 6 \mathrm{E})$. The films so obtained were cut, packed, sealed and stored at 40 ${ }^{\circ} \mathrm{C} / 75 \% \mathrm{RH}$ for $30 \mathrm{~d}$. The films were evaluated initially and after a period of $30 \mathrm{~d}$ for chemical degradation.

\section{Preparation of KT films using different $\mathrm{pH}$ conditions}

To evaluate the role of $\mathrm{pH}$ in the stabilization of KT films, $\mathrm{pH}$ of the dispersion was adjusted to 3 (F6 pH3), 5 (F6 pH5) and 9 (F6 pH9) by adding $0.1 \mathrm{M} \mathrm{HCl}$ or $0.1 \mathrm{M} \mathrm{NaOH}$. The dispersions were then processed as mentioned in section 2.4 and casted films were stored at $40{ }^{\circ} \mathrm{C} / 75 \% \mathrm{RH}$ for $30 \mathrm{~d}$. The films were evaluated initially and after a period of $30 \mathrm{~d}$ for the determination of impurities.

\section{RESULTS AND DISCUSSION}

In the drug excipient compatibility studies the objective was to study the effect of temperature and moisture on the stability of KT in the physical mixtures with the various film-forming polymers. No impurities were detected after storing the physical mixtures at 40 ${ }^{\circ} \mathrm{C} / 75 \% \mathrm{RH}$ conditions. This establishes that KT is fairly stable in solid state conditions with the selected polymers.

The purpose of conducting KT excipient compatibility study was to study the effect of processing conditions on KT in presence of different film forming polymers. The effects were studied using IR spectroscopy and X-ray diffractometry. IR spectra of pure KT revealed characteristic peaks depicting the functional groups like amino, hydroxyl, carbonyl, etc. present in the KT structure (table 5).

Table 5: Characteristic peaks of pure KT

\begin{tabular}{llc}
\hline S. No. & Functional group & Peak no. \\
\hline 1 & O-H Stretch & 3449 \\
2 & N-H stretch & 3345 \\
3 & C-H Stretch & 2980 \\
4 & C=O stretch & 1593,1614 \\
5 & C=C Stretch & 1566,1545 \\
6 & O-H N-H Bending & 1492,1470 \\
7 & C-H bending & 1381,1310 \\
8 & C-N Stretch & 1275 \\
9 & Carboxylic O-H bending & 1431 \\
10 & Alcoholic C-O stretch & 1088,1045 \\
11 & =C-H In-plane bending & 895,799 \\
12 & $=$ C-H out of plane bending & 772,723 \\
\hline
\end{tabular}

The IR spectra of KT processed (fig. 1) in the presence of HPMC showed the shifting of some peaks. The sharp N-H peak at $3345 \mathrm{~cm}^{-1}$ and $\mathrm{C}-\mathrm{H}$ stretch at $2980 \mathrm{~cm}^{-1}$ was broadened and lowered in intensity indicating that these groups are interacting with HPMC. The $\mathrm{O}-\mathrm{H}$ peak at $3449 \mathrm{~cm}^{-1}$ got merged with the $\mathrm{N}-\mathrm{H}$ peak. There is a possibility of Hydrogen bonding between the KT OH and HPMC hydroxyl groups. The $\mathrm{C}=0$ stretch was slightly shifted from 1593 to $1591 \mathrm{~cm}^{-1}$ and it got merged with carboxylic $\mathrm{C}=\mathrm{C}$ stretch at $1566 \mathrm{~cm}$ ${ }^{1}$ suggesting both of these functional groups getting affected by the interaction. The alcoholic C-0 stretch at $1045 \mathrm{~cm}^{-1}$ was found to be broadened. A significant change in the region from $1600-1000 \mathrm{~cm}$ ${ }^{1}$ was observed suggesting the interaction of functional groups of KT with HPMC.

When the combination of HPMC and HPC was used, the processing resulted in significant changes in the peak shape and peak position. The changes in the spectra of KT2B resembled with that of KT1B indicating similar interactions occurring between KT and HPMC and HPC. This is due to similarity in the structures of both the polymers.

KT in the presence of Kollicoat showed a reduction in peak intensity in the N-H stretch, while C-H stretch was not affected. Additionally, $\mathrm{O}-\mathrm{H}$ peak merged with the $\mathrm{N}-\mathrm{H}$ peak. Both carbonyl and $\mathrm{C}=\mathrm{C}$ stretch were slightly shifted to the lower wavenumbers which may be due to the hydrogen bonding with the polymer. Alcoholic $\mathrm{C}-\mathrm{O}$ bend was also affected. Except for $\mathrm{OH}$ peaks, rest of the peaks retained their shape and were shifted to slightly lower intensities.

After processing KT with PEO, no significant changes were observed in IR spectra. Except that $\mathrm{O}-\mathrm{H}$ stretch was merged with $\mathrm{N}-\mathrm{H}$ stretch, rest of the peaks were shifted slightly to lower wave numbers in the same way as with Kollicoat IR. The C-H stretch exhibited a sharp peak with decreased intensity. So, it can be concluded that KT interacts with PEO in a different mechanism than that of other polymers.

In the presence of a mixture of HPMC and Kollicoat IR, the IR spectra of the processed sample showed mixed changes that were observed in the presence of individual polymers. N-H peak was unaffected while the $\mathrm{O}-\mathrm{H}$ peak got merged with the $\mathrm{N}-\mathrm{H}$ peak. Peaks of carbonyl groups in the area from 1600-1000 were slightly shifted to lower frequencies indicating that hydroxyl groups of tromethamine and carboxylic groups are participating in the interaction. This interaction is affecting the rest of the groups.

IR spectra of both KT6B reveals that PEO when present with HPMC is able to protect $\mathrm{N}-\mathrm{H}$ groups from interactions. The $\mathrm{C}-\mathrm{H}$ stretch shifted to a lower frequency. The remaining peaks exhibited minor negligible variation. To summarize, PEO shows little interactions with KT in comparison to other film-forming polymers.

The XRD diffractograms (fig. 2) of physical mixtures of KT with various excipients revealed that the strong crystalline nature of KT remained mostly intact when processed using selected film-forming polymers. The comparison of XRD diffractograms of the physical mixture of KT and HPMC with that of the processed powder showed the drastic change (fig. 2). The powder after processing was completely amorphous and no characteristic peaks of KT were observed. KT is water soluble which means it dissolves during dispersion formation and forms strong hydrogen bonds with HPMC. Therefore, while drying KT remains in the bonded form with HPMC as revealed by IR spectra of the processed powder and exists in the amorphous form as seen in XRD diffractogram $[19,20]$. 


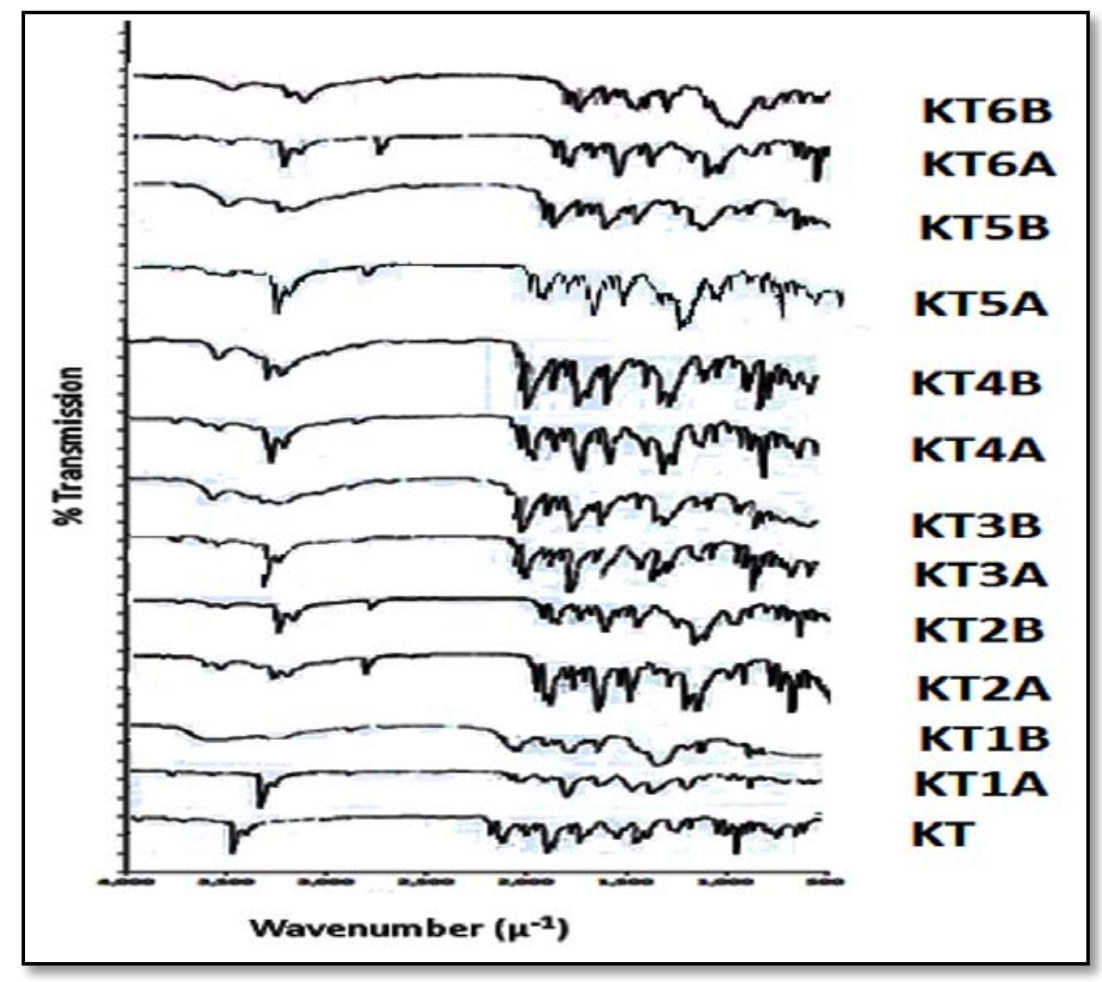

Fig. 1: IR spectra of pure KT, physical and processed mixtures of KT with excipients

The mixture of HPMC and HPC behaves differently than HPMC alone. The XRD diffractogram revealed retention of crystallinity of KT after processing and many characteristic peaks were observed in the processed sample. The mixture of KT and Kollicoat retained the crystalline nature of KT but some diffused peaks could also be seen indicating a mixture of crystalline and amorphous nature of both drug and excipient. The Processed mixture of KT with PEO exhibited both sharp and diffused peaks to the same extent indicating mixed product characteristics. KT, HPMC, and Kollicoat processed mixture also exhibited mixed characteristics, however, with the processed mixture of KT, HPMC and PEO nearly the same characteristics were seen as with their physical mixture. These findings revealed that when processed with HPMC, KT completely gets converted to amorphous form and with PEO crystalline form is retained. PEO also help KT to retain its crystalline structure even in present in combination with HPMC.

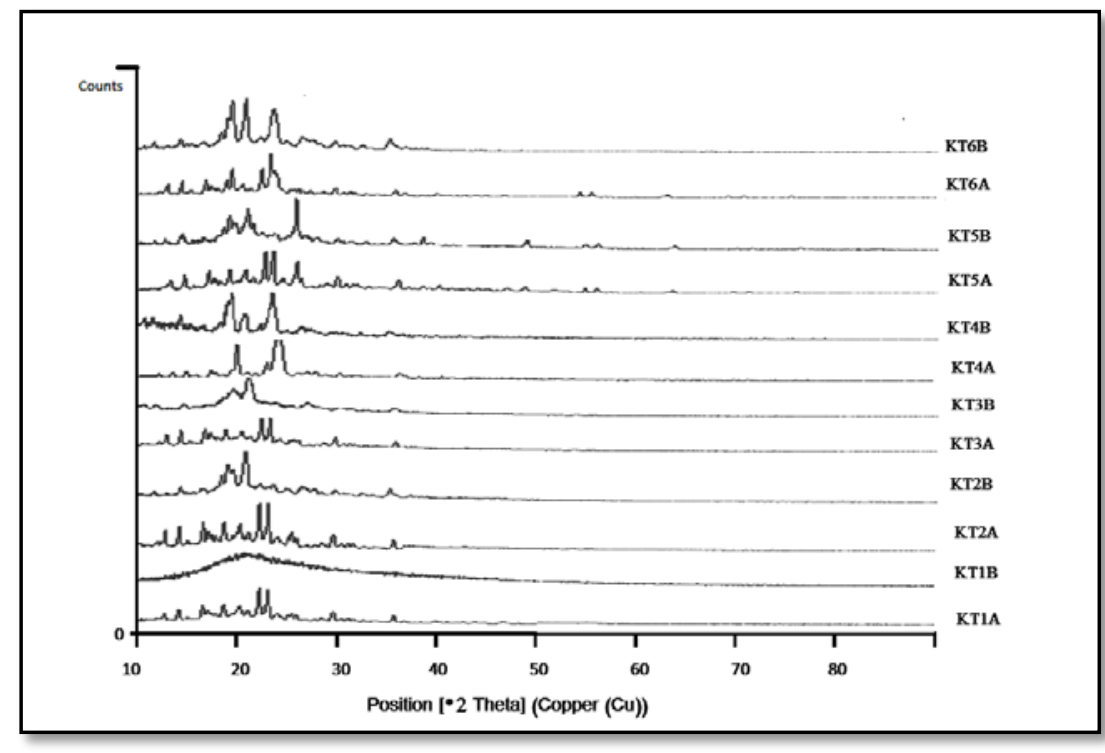

Fig. 2: XRD diffractograms of physical and processed mixtures of KT with excipients

The chemical analysis of KT films with different film-forming polymers revealed the effect of individual polymer on the chemical stability of KT. The initial impurities for the KT films were well below the specified limit (table 6). After one month period at $40{ }^{\circ} \mathrm{C} / 75 \% \mathrm{RH}$, KT films containing HPMC showed a drastic increase in total impurity level. This could be due to an interaction of HPMC with functional groups of KT, as revealed 
in IR spectroscopy. Further, complete amorphization of KT in presence of HPMC (as revealed by XRD) indicates that the amorphous form of KT is chemically unstable. Amorphous forms of KT in the presence of Hydroxypropyl- $\beta$-cyclodextrin, chitosan and gelatin are reported before [21, 22], but no studies on its chemical stability are reported. Least impurity level was observed with PEO, thus making it the most inert polymer followed by Kollicoat, but films produced by both of these polymers were not of desirable quality. F3 was brittle with poor folding endurance and F4 was sticky and tacky. The surface removal of both of these films was not good. The combination of HPMC with PEO had a lower impurity level than that of the combination of HPMC with Kollicoat. The reason for this must be the retention of crystallinity due to the presence of PEO. PEO must have prevented cross-linking of KT functional groups with HPMC by replacing some HPMC with itself during the polymerization process. Therefore, it was decided to continue further studies with F6.

Table 6: Impurity of KT with different polymers

\begin{tabular}{|c|c|c|c|c|c|c|c|c|c|c|c|c|}
\hline $\begin{array}{l}\text { Formulation } \\
\text { code }\end{array}$ & F1 & & F2 & & F3 & & F4 & & F5 & & F6 & \\
\hline Time points & Initial & $1 \mathrm{Mo}$ & Initial & $1 \mathrm{Mo}$ & Initial & $1 \mathrm{Mo}$ & Initial & $1 \mathrm{Mo}$ & Initial & $1 \mathrm{Mo}$ & Initial & $1 \mathrm{Mo}$ \\
\hline $\begin{array}{l}\text { Unknown } \\
\text { maximum } \\
\text { impurity } \\
\text { (NMT } 0.1 \% \text { ) }\end{array}$ & $\begin{array}{l}0.011 \pm 0 . \\
05\end{array}$ & $\begin{array}{l}1.644 \pm 0 . \\
08\end{array}$ & $\begin{array}{l}0.012 \pm 0 . \\
00\end{array}$ & $\begin{array}{l}0.056 \\
\pm 0.00\end{array}$ & ND & $\begin{array}{l}0.028 \pm \\
0.01\end{array}$ & $\begin{array}{l}0.006 \pm \\
0.00\end{array}$ & $\begin{array}{l}0.012 \pm 0 \\
.00\end{array}$ & $\begin{array}{l}0.005 \pm \\
0.00\end{array}$ & $\begin{array}{l}0.041 \pm \\
0.02\end{array}$ & ND & $\begin{array}{l}0.077 \pm \\
0.01\end{array}$ \\
\hline $\begin{array}{l}\text { Total } \\
\text { impurities } \\
\text { (NMT } 1.0 \% \text { ) }\end{array}$ & $\begin{array}{l}0.06 \pm 0.0 \\
6\end{array}$ & $\begin{array}{l}2.188 \pm 0 . \\
10\end{array}$ & $\begin{array}{l}0.073 \pm 0 . \\
00\end{array}$ & $\begin{array}{l}1.98 \pm \\
0.08\end{array}$ & $\begin{array}{l}0.056 \pm 0 \\
.00\end{array}$ & $\begin{array}{l}0.478 \pm \\
0.05\end{array}$ & $\begin{array}{l}0.054 \pm \\
0.00\end{array}$ & $\begin{array}{l}0.314 \pm 0 \\
.07\end{array}$ & $\begin{array}{l}0.064 \pm \\
0.00\end{array}$ & $\begin{array}{l}3.795 \pm \\
0.15\end{array}$ & $\begin{array}{l}0.056 \pm \\
0.00\end{array}$ & $\begin{array}{l}0.687 \pm \\
0.05\end{array}$ \\
\hline
\end{tabular}

Data are given in mean \pm SD, number of experiments $(n): 3$

It was thought that as $\mathrm{KT}$ is soluble in water during the solvent casting process, evaporation of water must be leading to reprecipitation of KT which precipitates in amorphous form. In the previous study with different film-forming polymers, it was revealed that the polymers that exhibited little interaction in IR and XRD yielded stable films. Therefore, it was decided to use hydro-alcoholic solvents in various concentrations to reduce the solubility of KT. The limit of impurities for KT films prepared using water alone and in combination with a non-aqueous solvent were also well below the specified limit initially (table 7). After one month at $40{ }^{\circ} \mathrm{C} / 75 \% \mathrm{RH}$, impurity level increased with an increase in the amount of nonaqueous solvent which, however, remained almost constant after certain water: non-aqueous solvent ratio. This indicates that alcoholic solvents act as reaction initiators for chemical degradation reactions of KT and therefore, water maintains the stability of KT in films dosage form better than non-aqueous solvents.

Table 7: Impurity in KT films using different solvents

\begin{tabular}{|c|c|c|c|c|c|c|c|c|}
\hline Formulation code & F6 & & F6A & & F6B & & F6C & \\
\hline Time points & Initial & $1 \mathrm{Mo}$ & Initial & $1 \mathrm{Mo}$ & Initial & $1 \mathrm{Mo}$ & Initial & $1 \mathrm{Mo}$ \\
\hline $\begin{array}{l}\text { Unknown maximum impurity } \\
\text { (NMT } 0.1 \% \text { ) }\end{array}$ & ND & $0.077 \pm 0.01$ & $0.05 \pm 0.00$ & $0.26 \pm 0.05$ & $0.006 \pm 0.00$ & $0.504 \pm 0.07$ & $0.007 \pm 0.00$ & $0.22 \pm 0.05$ \\
\hline Total impurities (NMT 1.0\%) & $0.056 \pm 0.00$ & $0.687 \pm 0.05$ & $0.045 \pm 0.00$ & $2.28 \pm 0.08$ & $0.06 \pm 0.00$ & $2.656 \pm 0.13$ & $0.054 \pm 0.00$ & $2.428 \pm 0.14$ \\
\hline
\end{tabular}

Data are given in mean \pm SD, number of experiments $(n): 3$

Since temperature plays a very important role in chemical reactions, KT films were dried at different temperatures. As expected, the initial impurity level was found to be within limits at all temperatures (table 8). However, the impurity level after one month period at $40{ }^{\circ} \mathrm{C} / 75 \% \mathrm{RH}$ was found to be in increasing order with a decrease in casting temperature. Temperature-dependent degradation of KT has been reported earlier but that was done only in powder blends and no effect of processing conditions was reported [23]. This could be due to the exposure of KT for longer durations at lower temperatures as compared to a shorter duration at the higher temperature.

Table 8: Impurity in KT films prepared at different temperatures

\begin{tabular}{|c|c|c|c|c|c|c|}
\hline Formulation code & F6 $\left(70^{\circ} \mathrm{C}\right)$ & & F6D $\left(50^{\circ} \mathrm{C}\right.$ & & F6E $\left(40^{\circ} \mathrm{C}\right)$ & \\
\hline Time points & Initial & $1 \mathrm{Mo}$ & Initial & $1 \mathrm{Mo}$ & Initial & $1 \mathrm{Mo}$ \\
\hline Unknown maximum impurity (NMT $0.1 \%$ ) & ND & $0.077 \pm 0.01$ & ND & $0.198 \pm 0.03$ & $0.006 \pm 0.00$ & $0.224 \pm 0.06$ \\
\hline Total impurities (NMT $1.0 \%$ ) & $0.056 \pm 0.00$ & $0.687 \pm 0.05$ & $0.06 \pm 0.00$ & $1.89 \pm 0.09$ & $0.055 \pm 0.00$ & $2.28 \pm 0.14$ \\
\hline
\end{tabular}

Data given in mean \pm SD, number of experiments (n): 3

Literature reveals that KT exhibits pH-dependent degradation, therefore the effect of $\mathrm{pH}$ on stability of KT films was studied by preparing casting dispersion at different $\mathrm{pH}$. KT films prepared at different dispersion $\mathrm{pH}$ of 3, 5 and 9 had initial impurities within limits (table 9). However, these initial impurities decreased with an increase in $\mathrm{pH}$. The dispersion with $\mathrm{pH} 3$ showed the highest initial impurity. After a period of one month, however, impurities at $\mathrm{pH} 5$ were found to be the highest while at $\mathrm{pH} 3$ it remained the same. Lower $\mathrm{pH}$ can thus be considered to keep KT stable in films as reported earlier [23].

Table 9: Impurity in KT films prepared at different $\mathrm{pH}$

\begin{tabular}{|c|c|c|c|c|c|c|}
\hline Formulation code & F6 pH3 & & F6 pH5 & & F6 pH9 & \\
\hline Time points & Initial & $1 \mathrm{Mo}$ & Initial & $1 \mathrm{Mo}$ & Initial & $1 \mathrm{Mo}$ \\
\hline Unknown maximum impurity (NMT $0.1 \%$ ) & $0.131 \pm 0.07$ & $0.131 \pm 0.07$ & $0.108 \pm 0.05$ & $0.338 \pm 0.03$ & $0.078 \pm 0.00$ & $0.121 \pm 0.01$ \\
\hline Total impurities (NMT 1.0\%) & $0.345 \pm 0.05$ & $0.345 \pm 0.07$ & $0.219 \pm 0.08$ & $0.870 \pm 0.09$ & $0.193 \pm 0.05$ & $0.402 \pm 0.06$ \\
\hline
\end{tabular}

Data given in mean $\pm S D$, number of experiments (n): 3 


\section{CONCLUSION}

KT was found to be stable in the presence of excipients during solid-state excipient compatibility studies. It was found that the stability of KT is affected by the nature of film-forming polymers. HPMC showed higher interaction affecting both physical and chemical stability of KT. PEO, on the other hand, was found to be the most inert polymer maintaining the stability of KT efficiently followed by Kollicoat. Water as a solvent system maintained the ability of KT in films as compared to its combination with a non-aqueous solvent. Higher drying temperatures reduced the travel time during casting operation which in turn lowered the degradation process. It can also be said that maintaining an acidic $\mathrm{pH}$ during the formulation stages gives more stable KT films. In conclusion, both formulation and process parameters affect the stability of KT in an orally dissolving film dosage form.

\section{AUTHORS CONTRIBUTIONS}

All the author have contributed equally

\section{CONFLICT OF INTERESTS}

Declared none

\section{REFERENCES}

1. Indian Pharmacopoeia. Volume II; 2014. p. 2037-8.

2. Kalariya PD, Raju B, Borkar RM, Namdev D, Gananadhamu S, Nandekar PP, et al. Characterization of forced degradation products of ketorolac tromethamine using LC/ESI/Q/TOF/MS/MS and in silico toxicity prediction. J Mass Spectrom 2014;49:380-91.

3. Salaris M, Nieddu M, Rubattu N, Testa C, Luongo E, Rimoli MG, et al. Acid and base degraded product of ketorolac. J Pharm Biomed Anal 2010;52:320-2.

4. Devarajan PV, Gore SP, Chavan SV. HPTLC determination of ketorolac tromethamine. J Pharm Biomed Anal 2000;22:679-83.

5. Leo G, Chiang H, Becker A. Kinetics and mechanisms of the autoxidation of ketorolac tromethamine in aqueous solution. Int J Pharm 1988;41:95-104.

6. Leo G, Chiang H, Johnson D. Light degradation of ketorolac tromethamine. Int J Pharm 1988;41:105-13.

7. Toradol Oral. Available from: https://www.accessdata. fda.gov/drugsatfda_docs/label/2013/019645s019lbl. pdf. [Last accessed on 15 Dec 2018]

8. Ketorolac Tromethamine Injection. Available from: https://www.accessdata.fda.gov/drugsatfda_docs/appletter/2 016/2042160rig1s000ltr.pdf. [Last accessed on 15 Dec 2018]

9. Sprix Nasal Spray. Available from: https:// www.accessdata.fda.gov/drugsatfda_docs/label/2010/022382 s000lbl.pdf. [Last accessed on 15 Dec 2018]
10. Acular Ophthalmic solution. Available from: https://www.accessdata.fda.gov/drugsatfda_docs/label/2005/ 19700S023,024lbl.pdf. [Last accessed on 15 Dec 2018]

11. Kumar De P, Mallick S, Mukherjee B, Sengupta S, Pattnaik S, Chakraborty S. Optimization of in vitro permeation pattern of ketorolac tromethamine transdermal patches. Iranian J Pharm Res 2011;10:193-201.

12. Xu ZP, Gu Z, Cheng X, Rasoul F, Whittaker AK, Max Lu GQ. Controlled release of ketorolac through nanocomposite films of hydrogel and LDH nanoparticles. J Nanopart Res 2011;13:1253-64.

13. Rudra VS, Birla RV, Katakam M, Inventors. Sublingual film of ketorolac. Patent Application No. WO2016151461A1; 2016.

14. El-Nabarawi MA, Makky AM, El-Setouhy DA, ABD Elmonem RA, Jasti BA. Development and characterization of ketorolac tromethamine (KT) orobuccal films. Int J Pharm Pharm Sci 2012;4:186-93

15. Katdare A, Chaubal M. Excipient development for pharmaceutical, biotechnology, and drug delivery systems. Taylor and Francis Group LLC; 2006. p. 101-4.

16. Hoffmann EM, Breitenbach A, Breitkreutz J. Advances in orodispersible films for drug delivery. Expert Opin Drug Delivery 2011;8:299-316.

17. Daud AS, Sapkal NP, Bonde MN. Development of Zingiber officinale in oral dissolving films: Effect of polymers on in vitro, in vivo parameters and clinical efficacy. Asian J Pharm 2011;5:183-9.

18. Daud AS, Sapkal NP, Bonde MN, Gaikwad N. To study the effect of solvent, viscosity, and temperature on the mouth-dissolving film of Withania somnifera linn. Asian J Pharm 2012;6:212-7.

19. Ivanisevic I. Physical stability studies of miscible amorphous solid dispersions. J Pharm Sci 2010;99:4005-12.

20. Meng F, Trivino A, Prasad D, Chauhan H. Investigation and correlation of drug-polymer miscibility and molecular interactions by various approaches for the preparation of amorphous solid dispersions. Eur J Pharm Sci 2015;71:12-24.

21. Nagarsenker MS, Meshram RN, Ramprakash G. Solid dispersion of hydroxypropyl-beta-cyclodextrin and ketorolac: enhancement of in vitro dissolution rates, improvement in anti-inflammatory activity and reduction in ulcerogenicity in rats. J Pharm Pharmacol 2000;52:949-56.

22. Basu SK, Kavitha K, Rupeshkumar M. Evaluation of ketorolac tromethamine microspheres by chitosan/gelatin B complex coacervation. Sci Pharm 2010;78:79-92.

23. Brandl M, Magil A, Rudraraju V, Gordon MS. Approaches for improving the stability of ketorolac in powder blends. J Pharm Sci 1995;84:1151-3. 